\title{
Asthma, atopy and tuberculin responses in Chinese schoolchildren in Hong Kong
}

\author{
G W K Wong, D S C Hui, C M Tam, H H Chan, T F Fok, M Chan-Yeung, C K W Lai
}

Department of

Paediatrics, Prince of

Wales Hospital, The

Chinese University of

Hong Kong, Shatin,

New Territories, Hong

Kong Special

Administrative

Region, China

G W K Wong

T F Fok

Department of

Medicine and

Therapeutics, Prince

of Wales Hospital

D S C Hui

H H Chan

C K W Lai

Chest Service Central Office, Department of Health

C M Tam

Department of

Medicine, The

University of Hong

Kong,

M Chan-Yeung

Correspondence to:

Dr G W K Wong

wingkinwong@cuhk.edu.hk

Received 15 January 2001 Returned to authors

14 March 2001

Revised version received

21 May 2001

Accepted for publication

15 June 2001

\begin{abstract}
Background-The prevalence rates of asthma and other atopic disorders have increased steadily in many developed countries over the past few decades. Recent epidemiological and animal studies have suggested that BCG vaccination might be beneficial in reducing the subsequent development of atopy. This study investigates the relationship between asthma, allergic symptoms, atopy, and tuberculin response in Chinese schoolchildren who received BCG vaccination at birth.

Methods-A total of 3110 schoolchildren aged 10 years were recruited for the Hong Kong arm of the phase II International Study of Asthma and Allergies in Childhood. Of the 2599 children born in Hong Kong and vaccinated with BCG after birth, 2201 had tuberculin testing performed at a mean (SD) age of 8.4 (1.4) years. A random subsample of 980 children was also recruited for skin prick testing.

Results-The prevalence rates of asthma ever, wheeze ever, current wheeze, current rhinoconjunctivitis, and current flexural eczema were not significantly different between tuberculin positive and negative subjects. The mean (SE) tuberculin response was $3.4(0.2) \mathrm{mm}$ in atopic subjects and $3.3(0.2) \mathrm{mm}$ in non-atopic subjects (difference not significant). Logistic regression analyses did not reveal any significant relationship between asthma ever, current wheeze, atopy, and positive tuberculin responses.

Conclusions-This study did not find any relationship between asthma, allergic symptoms, atopy, and positive tuberculin reactivity in Chinese schoolchildren vaccinated with BCG at birth.

(Thorax 2001;56:770-773)
\end{abstract}

Keywords: asthma; atopy; tuberculosis; immunisation; children

The prevalence rates of asthma and other atopic diseases have increased steadily in many countries. ${ }^{1-4}$ The reasons for the increase are largely unknown, but environmental factors have been thought to be important in causing such an increase. It has been postulated that a reduction in bacterial and viral infections as a result of improvement in living standards and implementation of comprehensive immunisation programmes may have contributed to the recent epidemic of allergic disorders. ${ }^{56}$
$\mathrm{T}$ helper (Th) lymphocytes play a central role in the development of asthma and atopy. Their immunological responses can be classified into Th1 and Th2 according to their production of cytokines. ${ }^{7}$ Th 1 cells are characterised by the production of interferon $\gamma$ (IFN $\gamma$ ) and tumour necrosis factor (TNF) when stimulated with virus or bacteria. In contrast, Th2 cells, when stimulated with allergens or parasites, produce interleukin (IL)-4, IL-5 IL-6, and IL-13 which are important in promoting IgE production by $\mathrm{B}$ lymphocytes. ${ }^{78}$ The predominant immune response in atopic subjects is of the Th2 type. BCG vaccination is known to induce a Th1 type response resulting in the secretion of IFN $\gamma$ as one of the major cytokines. ${ }^{9}{ }^{10}$ Shirakawa et al studied a group of Japanese schoolchildren from Wakayama and reported a protective role of a positive tuberculin response in the development of atopic diseases. ${ }^{11}$ However, two subsequent studies failed to confirm the relationship between BCG vaccination and atopy in children. ${ }^{12} 13$

In Hong Kong there has been a long established official policy of BCG vaccination for all newborn infants within 1-2 days after birth. All schoolchildren are invited for tuberculin testing at the age of $7-10$ years by the Department of Health and, if their responses are negative ( $<10 \mathrm{~mm}$ induration), they will be revaccinated. In the present study we investigate the relationship between asthma, allergic symptoms, atopy, and tuberculin response in the children who participated in the International Study of Asthma and Allergies in Childhood (ISAAC) from Hong Kong.

\section{Methods}

STUDY POPULATION

Schoolchildren aged 10 years (10 years 0 months to 10 years 11 months) were targeted for the study following the ISAAC phase II protocol. ${ }^{14}$ There were a total of 616 primary schools in Hong Kong with approximately 90000 schoolchildren in the target age range (grade 5). Sixty eight of these schools were excluded from the study because they had fewer than 100 children in the target age group; the remaining 548 schools were individually allocated a number and a list of 30 schools was generated by computer randomisation.

Each school was invited to take part in the study in descending order down the list. Twenty three schools agreed to participate and were able to provide 3215 schoolchildren aged 10 years as potential subjects. These schools and those 68 schools with fewer than 100 children in the target age group were distributed 
Table 1 Demographic data and responses to written questionnaire of subjects with BCG vaccination after birth in Hong Kong

\begin{tabular}{lcc}
\hline & All subjects $(n=2583)$ & $\begin{array}{l}\text { Subjects with tuberculin } \\
\text { testing }(n=2201)\end{array}$ \\
\hline Sex & $1376(53.3)$ & $1167(53.0)$ \\
$\quad$ Boys & $1207(46.7)$ & $1034(47.0)$ \\
Girls & $8(0.3)$ & $7(0.3)$ \\
$\quad<10$ years & $2263(87.6)$ & $1949(88.6)$ \\
10 years & $312(12.1)$ & $245(11.1)$ \\
$\quad \geqslant 11$ years & $336(13.0)$ & $277(12.6)$ \\
Wheeze ever & $223(8.6)$ & $187(8.5)$ \\
Asthma ever & $170(6.6)$ & $141(6.4)$ \\
Current wheeze & $419(16.2)$ & $365(16.6)$ \\
Current rhinoconjunctivitis & $112(4.3)$ & $98(4.5)$ \\
Current flexural eczema & & \\
\hline
\end{tabular}

Data are numbers (\%).

randomly throughout the territory. Informed parental consent was obtained from parents or guardians and 3110 agreed to enroll their children in the study, representing a response rate of $97 \%$.

QUESTIONNAIRES

Each subject was given an ISAAC phase II questionnaire to be completed by the parents or guardians. The written questionnaire was translated into Chinese following the ISAAC protocol. This involved an independent person who was bilingual to translate the original English questionnaire into Chinese. Another bilingual person then back translated this into English. The translated questionnaire was pilot tested in a group of parents and necessary modifications were made before the survey was carried out. The ISAAC phase II questionnaire asked for information on demography, symptoms of wheeze, asthma, rhinitis and eczema, together with various possible risk factors. "Current" symptoms referred to symptoms in the past 12 months; "asthma ever" was defined as having been diagnosed with asthma by a physician sometime in the subjects' lifetime; "rhinoconjunctivitis" was defined as sneezing or having a runny nose or blocked nose accompanied by itchy-watery eyes when the subject did not have an upper respiratory tract infection; "flexural eczema" was defined as an itchy rash which was coming and going for at least 6 months affecting the folds of the elbows, behind the knees, in front of the ankles, under the buttocks or around the neck, ears, or eyes. In addition, a question on the place of birth was also included as some children were recent immigrants from China and might not have been vaccinated with BCG after birth.

The official policy in Hong Kong is to vaccinate all newborn babies 1-3 days after birth with the Glaxo strain of BCG (Glaxo Laboratories, UK) and to record this on their immunisation card. BCG vaccination is verified by checking the immunisation record and the presence of a BCG scar during subsequent visits for routine immunisation. The coverage of BCG vaccination for newborn babies has persistently been documented to be over $98 \%$ since $1980 .{ }^{15}$ Only children born in Hong Kong were included in the study as those born outside Hong Kong might not have received vaccination after birth.
SKIN PRICK TEST

A total of 2023 subjects (65\%) also gave consent for skin prick testing and children were randomly recruited for skin prick tests performed according to the standardised ISAAC protocol. ${ }^{14}$ The sensitivity to eight common aeroallergens was assessed: Dermatophagoides pteronyssinus, D farinae, cat, Alternaria tenuis, mixed tree pollen, mixed grass pollen, cockroach, and mixed moulds. Standardised allergen extracts and control solutions were obtained from ALK (Horsholm, Denmark). Histamine $(10 \mathrm{mg} / \mathrm{ml})$ and diluent were used as positive and negative controls. The weal reaction after 15 minutes was measured as the mean of the longest diameter and the length of the perpendicular line through its middle, a weal size of $\geqslant 3 \mathrm{~mm}$ after subtraction of the negative control being considered positive. Subjects with one or more positive reactions were considered atopic.

TUBERCULIN TESTING

Children are routinely tested for their tuberculin responses at the age of 7-10 years. One tuberculin unit PPD-RT23 is given intradermally on the volar surface of the forearm and the maximum diameter of the PPD induration is recorded after 72 hours. The results of the tuberculin responses of the subjects were retrieved from the records of the Department of Health of the Hong Kong Government. The written questionnaire surveys were conducted between October 1997 and February 1998 while the skin prick tests were performed between March and May 1998.

\section{ANALYSIS OF DATA}

All data were entered into a computer twice by two independent investigators. Data were categorised and analysed using the Statistical Package for the Social Sciences (SPSS) for Windows Release 10.0 (Maija J Norusis/SPSS Inc, 1999). Statistical analysis was performed using the Student's $t$ test, $\chi^{2}$ test, and multiple logistic regression with adjustment for age and sex to test the possible associations between a positive tuberculin response $(\geqslant 10 \mathrm{~mm})$ and the dependent variables (current wheeze, current rhinoconjunctivitis, current flexural eczema, wheeze ever, asthma ever, and atopic status). The results are presented as odds ratios (OR) and $95 \%$ confidence intervals (CI). A p value of $<0.05$ was considered to be significant.

\section{Results}

Of the 3110 children recruited, 2599 (84\%) were born in Hong Kong and had BCG vaccination at birth. Sixteen were excluded because of a history of tuberculosis and the subsequent analyses were based on the remaining 2583 children. Of these, 2201 (85.2\%) had tuberculin testing after parental consent was obtained. The mean (SD) age at which tuberculin testing was performed was 8.5 (1.4) years. The prevalence of asthma and atopic symptoms in the subgroup of children who had tuberculin testing was virtually identical to that in the whole group (table 1). The demographic characteristics and prevalence rates of asthma and atopic 
Table 2 Prevalence of atopic sensitisation: comparison of tuberculin positive and negative subjects

\begin{tabular}{lll}
\hline Allergen $^{*}$ & $\begin{array}{l}\text { Positive subjects } \\
(n=165)\end{array}$ & $\begin{array}{l}\text { Negative subjects } \\
(n=815)\end{array}$ \\
\hline$\geqslant 1$ positive skin test result & $68(41.2)$ & $356(43.7)$ \\
D pteronyssinus & $58(35.2)$ & $294(36.1)$ \\
D farinae & $43(26.1)$ & $220(27.0)$ \\
Cockroach & $19(11.5)$ & $99(12.1)$ \\
\hline
\end{tabular}

Data are numbers (\%).

* Sensitisation to other allergens was uncommon (data not shown) and not significantly different between the two groups.

Table 3 Demographic data and tuberculin responses of atopic and non-atopic subjects

\begin{tabular}{lll}
\hline & $\begin{array}{l}\text { Atopic } \\
(n=424)\end{array}$ & $\begin{array}{l}\text { Non-atopic } \\
(n=556)\end{array}$ \\
\hline $\begin{array}{l}\text { Mean (SD) age (years) } \\
\text { Tuberculin responses, } \mathrm{n}(\%)^{\star}\end{array}$ & $10.1(0.3)$ & $10.1(0.3)$ \\
$\quad<5 \mathrm{~mm}$ & $298(70.3)$ & $384(69.1)$ \\
$\quad 5-9 \mathrm{~mm}$ & $58(13.7)$ & $75(13.5)$ \\
$\quad \geqslant 10 \mathrm{~mm}$ & $68(16.0)$ & $97(17.4)$ \\
Mean (SE) weal (mm) $\dagger$ & $3.4(0.2)$ & $3.3(0.2)$ \\
\hline${ }^{\star} \chi^{2}=0.34, \mathrm{p}=0.8$. & & \\
$\dagger t$ test, $\mathrm{p}=0.9$. & &
\end{tabular}

symptoms are summarised in table 1 . A random subsample of 980 children also underwent skin prick testing. The prevalence of allergic symptoms and asthma ever in this subgroup of children was not significantly different from that of the whole group (data not shown). Of these 980 children, $424(43.3 \%)$ had one or more positive skin test results. The prevalence rates of sensitisation to various antigens are shown in table 2. No difference in the prevalence rates between the tuberculin positive and tuberculin negative groups was found.

Of the 2201 children who underwent tuberculin testing, $1537(69.8 \%)$ had a response of $<5 \mathrm{~mm}, 305(13.9 \%)$ had a response of 5-9 $\mathrm{mm}$, and $359(16.3 \%)$ had a response of $\geqslant 10 \mathrm{~mm}$. Table 3 shows the comparison of tuberculin responses between the atopic and non-atopic subjects. The distribution of tuberculin responses did not differ between the two groups $\left(\chi^{2}=0.34 ; \mathrm{p}=0.8\right)$. The mean (SE) tuberculin response was $3.4(0.2) \mathrm{mm}$ in atopic subjects and $3.3(0.2) \mathrm{mm}$ in non-atopic subjects $(t$ test, $\mathrm{p}=0.9)$. The prevalence rates of asthma ever and various atopic symptoms in

Table 4 Responses to written questionnaire: comparison of tuberculin positive and negative subjects

\begin{tabular}{|c|c|c|c|c|}
\hline & \multicolumn{2}{|c|}{ Positive subjects $(n=359)$} & \multicolumn{2}{|c|}{ Negative subjects $(n=1842)$} \\
\hline & $\%$ & $95 \% C I$ & $\%$ & $95 \% C I$ \\
\hline Wheeze ever & 12.0 & 8.8 to 15.8 & 12.7 & 11.2 to 14.3 \\
\hline Asthma ever & 9.2 & 6.4 to 12.7 & 8.4 & 7.2 to 9.7 \\
\hline Current wheeze & 7.2 & 4.8 to 10.4 & 6.2 & 5.2 to 7.5 \\
\hline Current rhinoconjunctivitis & 15.6 & 12.0 to 19.8 & 16.8 & 15.1 to 18.6 \\
\hline Current flexural eczema & 2.8 & 1.3 to 5.1 & 4.8 & 3.9 to 5.8 \\
\hline
\end{tabular}

Table 5 Logistic regression analyses * of relationship between asthma, allergic symptoms, atopy, and positive tuberculin response in the study subjects

\begin{tabular}{llll}
\hline & OR & $95 \%$ CI & $p$ Value \\
\hline Wheeze ever & 0.99 & 0.70 to 1.40 & 0.93 \\
Asthma ever & 1.16 & 0.78 to 1.72 & 0.47 \\
Current wheeze & 1.24 & 0.80 to 1.93 & 0.35 \\
Current rhinoconjunctivitis & 0.94 & 0.67 to 1.28 & 0.68 \\
Current flexural eczema & 0.58 & 0.30 to 1.13 & 0.11 \\
Atopy & 0.98 & 0.70 to 1.39 & 0.92 \\
\hline
\end{tabular}

${ }^{\star}$ Sex and age are included in the logistic regression model.

$\mathrm{OR}=$ odds ratio $; 95 \% \mathrm{CI}=95 \%$ confidence interval. subjects with positive and negative tuberculin responses are shown in table 4. Again, no difference was found between the two groups. Furthermore, multivariate logistic regression analyses with adjustment for age and sex did not reveal any significant relationship between asthma ever, wheeze ever, current wheeze, current rhinoconjunctivitis, current eczema, atopy, and positive tuberculin response (table 5)

\section{Discussion}

This study shows that a positive tuberculin response $(\geqslant 10 \mathrm{~mm})$ has no correlation with asthma and atopy in Hong Kong Chinese schoolchildren vaccinated with BCG at birth. The distribution of the magnitude of tuberculin responses was the same among atopic and non-atopic children (table 3).

Because of the long established policy of BCG vaccination of all newborn children after birth in Hong Kong, we were able to investigate the possible relationship between tuberculin responses and atopic diseases in a large group of children. The study population, drawn randomly from the primary schools of Hong Kong, should be representative because school attendance until the completion of grade 9 is compulsory. The children were recruited for the Hong Kong arm of the ISAAC phase II study which has an excellent participation rate of $97 \%$. Their tuberculin testing was performed approximately 1.5 years before the written questionnaire. Although tuberculin testing was not performed in $382(14.8 \%)$ children because of parental refusal, the demographic characteristics, prevalence rates of asthma, and allergic symptoms were virtually identical in those in the whole group and those who underwent tuberculin testing (table 1).

Shirakawa et $a l^{11}$ reported that positive tuberculin responses among Japanese schoolchildren aged $12-13$ years is associated with a lower incidence of atopic disorders. Furthermore, positive tuberculin responses were associated with lower IgE levels and dominance of Th1 over Th2 in the peripheral blood cytokine profiles at 12 years of age. The authors suggested that BCG vaccination and exposure to mycobacteria might reduce the development of atopic disease by promoting Th1 immunity. There have also been recent animal studies showing that BCG vaccination could suppress allergic induced airway eosinophilia and hyperreactivity in mice by stimulating a Th1 type response. ${ }^{1617}$ von Mutius et $a l^{18}$ analysed the relationship between tuberculosis notification rates and the prevalence of atopic diseases obtained from the ISAAC phase I results and found that tuberculosis notification rates were significantly inversely associated with the prevalence of wheeze and asthma in schoolchildren. Another study from Finland by von Hertzen et $a l^{19}$ showed that tuberculosis infection in childhood significantly reduced the occurrence of subsequent asthma in women.

In contrast, a recent study by Alm et $a l^{12}$ from Sweden, in which the analysis focused on children with a strong family history of atopy, found that the rates of atopic disorder were 
similar in preschool children given BCG immunisation before 6 months of age to those who had not received BCG. A study by Yilmaz et $a l^{13}$ from Turkey did not find any relationship between tuberculin response and atopy in 8 year old children who were vaccinated with BCG at birth and at 6 years of age, and Omenaas et $a l^{20}$ also did not find any relationship between tuberculin reactivity and atopy in young adult Norwegians who had received BCG vaccination at 14 years of age. The authors concluded that, even if a true relationship exists between tuberculin reactivity and atopy, such a relationship may only hold when the population was immunised early in life. The current study is a large population based study in Chinese children in Hong Kong and our results did not reveal any relationship between asthma, allergic symptoms, atopy, and tuberculin reactivity in subjects vaccinated with BCG at birth. Since the tuberculin testing was performed 1.5 years before the written questionnaire survey, there is an unlikely possibility that some children might have changed their tuberculin status after revaccination which would have affected the development of symptoms in the last 12 months.

It appears that firm conclusions regarding the possible benefit from BCG vaccination in the reduction of atopy are difficult to draw from the reported studies. Hopkin suggested that other uncontrolled but important genetic and co-exposure variables might affect the results of the reported retrospective studies. ${ }^{21}$ Prospective controlled trials are therefore necessary to test the potential benefits of BCG vaccination on the development of atopic disorders later in life.

The study was supported by Research Grant Council Earmarked Grant $96 / 97$ No. CUHK 232/96M. The authors wish to thank M Tong, A Chan, C Chan, and K K Wong for their technical support, and the children, parents and staff of the their technical support, and the children, pare
schools for their participation in the survey.
1 Aberg N, Hesselmar B, Aberg B, et al. Increase of asthma, allergic rhinitis and eczema in Swedish schoolchildren allergic rhinitis and eczema in Swedish schoolchildre

2 Burr ML, Butland BK, King S, et al. Changes in asthma prevalence: two surveys 15 years apart. Arch Dis Child 1989;64:1118-25.

3 Shaw RA, Crane J, O'Donnell TV, et al. Increasing asthma prevalence in a rural New Zealand adolescent population. 1975-89. Arch Dis Child 1990;65:1319-23.

4 Venn A, Lewis S, Cooper M, et al. Increasing prevalence of wheeze and asthma in Nottingham primary schoolchildren wheeze and asthma in Nottingham primary

5 Martinez FD. Role of viral infections in the inception of asthma and allergies during childhood: could they be protective? Thorax 1994;49:1189-91

6 Strachan DP. Family size, infection and atopy: the first decade of the "hygiene hypothesis". Thorax 2000;55:S2-10.

7 Romagnani S. Induction of Th1 and Th2 responses: a key role for the "natural" immune response? Immunol Today 1992;13:379-81.

8 Del Prete G. Human Th1 and Th2 lymphocytes: their role in the pathophysiology of atopy. Allergy 1992;47:450-5.

9 Sander B, Skansen-Saphir U, Damm O, et al. Sequential Sander B, Skansen-Saphir U, Damm O, et al. Sequential
production of Th1 and Th2 cytokines in response to live production of Th1 and Th2 cytokines in response to live

10 Dauglelat S, Ladel CH, Kauffmann SH. Influence of mouse strain and vaccine viability on T-cell responses induced by Mycobacterium bovis and baccillus Calmette-Guerin. Infect Immun 1995;63:2033-40.

11 Shirakawa T, Enomoto T, Shimazu S, et al. The inverse association between tuberculin responses and atopic disorder. Science 1997;275:77-9.

12 Alm JS, Lilja G, Pershagen G, et al. Early BCG vaccination and development of atopy. Lancet 1997;350:400-3.

13 Yilmaz M, Bingol G, Altintas D, et al. Correlation between atopic diseases and tuberculin responses. Allergy 2000;55: atopic

14 ISAAC Steering Committee. Phase II modules of the International Study of Asthma and Allergies in Childhood (ISAAC). Munster: ISAAC, 1998.

15 Department of Health. Hong Kong Department of Health Annual Report 1998/99. 2000:28.

16 Erb KJ, Holloway JW, Sobeck A, et al. Infection of mice with Mycobacterium bovis-baccillus-Guerin (BCG) suppresses allergen-induced airway eosinophilia. $\mathcal{F}$ Exp Med 1998;187: 561-9.

17 Herz U, Gerhold K, Gruber C, et al. BCG infection suppresses allergic sensitization and development of increased airway reactivity in animal model. $\mathcal{F}$ Allergy Clin Immunol 1998;102:867-74.

18 von Mutius E, Pearce N, Beasley R, et al. International patterns of tuberculosis and prevalence of symptoms of asthma, rhinitis, and eczema. Thorax 2000;55:449-53.

19 von Hertzen L, Klaukka T, Mattila H, et al. Mycobacterium tuberculosis infection and the subsequent development of asthma and allergic conditions. F Allergy Clin Immunol 1999;104:1211-4

20 Omenaas E, Jentoft HF, Vollmer WM, et al. Absence of relationship between tuberculin reactivity and atopy in BCG vaccinated young adults. Thorax 2000;55:454-8.

21 Hopkin JM. Atopy, asthma and the mycobacteria. Thorax 2000;55:443-5. 